\title{
A New Chance for Hyperimmunized Patients in Renal Transplant Waiting List from Tolerance Induction: The Emerging Link between Human Leukocyte Antigen G, T-Regulatory Cells, and Neutrophil Gelatinase-Associated Lipocalin
}

\author{
Gaetano La Manna \\ Department of Experimental Diagnostic and Specialty Medicine (DIMES), Nephrology, Dialysis and Renal Transplant \\ Unit, St. Orsola Hospital, University of Bologna, Bologna, Italy
}

Dear Editor,

In recent years, the rising number of highly sensitized patients waiting for a kidney transplant has become an important problem for both dialysis and transplant physicians. The presence of alloantibodies against human leukocyte antigen (HLA) and non-HLA antigens in these patients results in positive crossmatches with almost all the potential organ donors, and prolongs the average time on waiting list under dialysis treatment [1]. In order to increase the chances for hyperimmunized candidates to receive a transplant, the traditional desensitization protocols utilize intravenous immunoglobulin infusions prior to transplantation, frequently combined with plasmapheresis in order to remove circulating antibodies [2]. However, the previously described desensitization approaches might fail in particularly sensitized patients who have a panel of reactive antibodies above 85\%, who may not achieve an acceptable crossmatch [3]. Thus, the health professionals are improving their efforts toward finding novel viable solutions for immune system modulation and tolerance induction in this disadvantaged category of patients.

A "hot topic" in this context is represented by T regulatory cells (Treg), a population firstly described in 1975 [4], able to control antigen-specific immune responses and elicit operational tolerance in transplant recipients [5]. Besides the described "classical" Treg $\left(\mathrm{CD} 4^{+} \mathrm{CD} 25^{+} \mathrm{FoxP} 3^{+}\right)$cells, the existence of another thymus-derived Treg cell subset, expressing the immune tolerizing molecule, HLA-G, has been shown to have potential advantageous implications in transplantation and autoimmune diseases $[6,7]$.

We have previously described the ability of neutrophil gelatinase-associated lipocalin (NGAL) to induce immune tolerance through expansion of Treg cells and HLA-G upregulation in peripheral blood mononuclear cell cultures from healthy subjects [8]. Our data have shed light on an unexpected role of NGAL, a molecule that in the last decade has raised much interest in the scientific community as a kid- ney injury marker $[9,10]$, indicating novel insights in immune modulation and a potential relevance for immunosuppressive therapy efficacy, tolerance induction after transplant, and in patients with immunological disorders.

Given the initial encouraging results, our current research is evaluating the effects of NGAL exposure on expansion of Tregs and HLA-G expression in cells from hyperimmunized patients under hemodialysis treatment in waiting list for kidney transplant. We expect that this attractive emerging link between Tregs, HLA-G, and NGAL in tolerance induction might open a new scenario in terms of immune modulation before or during kidney transplant in these complex patients, increasing their chances for a successful transplant.

\section{Disclosure Statement}

The author has declared no competing interest.
Gaetano La Manna, MD, PhD

Department of Experimental, Diagnostic and Specialty Medicine (DIMES) - Nephrology Dialysis and Transplantation Unit, St. Orsola Hospital, University of Bologna Via G. Massarenti 9 (Pad. 15), IT-40138 Bologna (Italy)

E-Mail gaetano.lamanna@unibo.it 


\section{References}

1 Gloor J: Kidney transplantation in the hyperimmunized patient. Contrib Nephrol 2005; 146:11-21.

2 Matignon M, Leibler C, Moranne O, Salomon L, Charron D, Lang P, Jacquelinet C, Suberbielle C, Grimbert P: Anti-HLA sensitization after kidney allograft nephrectomy: changes one year post-surgery and beneficial effect of intravenous immunoglobulin. Clin Transplant 2016;30:731-740.

3 Kozlowski T, Andreoni K: Limitations of rituximab/IVIg desensitization protocol in kidney transplantation; is this better than a tincture of time? Ann Transplant 2011;16:19-25.

4 Kilshaw PJ, Brent L, Pinto M: Suppressor T cells in mice made unresponsive to skin allografts. Nature 1975;255:489-491.
5 Dummer CD, Carpio VN, Gonçalves LF, Manfro RC, Veronese FV: FOXP3+ regulatory $\mathrm{T}$ cells: from suppression of rejection to induction of renal allograft tolerance. Transpl Immunol 2012;26:1-10.

6 Pankratz S, Ruck T, Meuth SG, Wiendl H: CD4(+)HLA-G(+) regulatory $\mathrm{T}$ cells: Molecular signature and pathophysiological relevance. Hum Immunol 2016;77:727733.

7 LeMaoult J, Krawice-Radanne I, Dausset J, Carosella ED: HLA-G1-expressing antigenpresenting cells induce immunosuppressive CD4+ T cells. Proc Natl Acad Sci U S A 2004 101:7064-7069.
8 La Manna G, Ghinatti G, Tazzari PL, Alviano F, Ricci F, Capelli I, Cuna V, Todeschini P, Brunocilla E, Pagliaro P, Bonsi L, Stefoni S: Neutrophil gelatinase-associated lipocalin increases HLA-G(+)/FoxP3(+) T-regulatory cell population in an in vitro model of PBMC. PLoS One 2014;9:e89497.

9 Devarajan P: Neutrophil gelatinase-associated lipocalin (NGAL): a new marker of kidney disease. Scand J Clin Lab Invest Suppl 2008; 241:89-94.

10 Ronco C, Legrand M, Goldstein SL, Hur M, Tran N, Howell EC, Cantaluppi V, Cruz DN, Damman K, Bagshaw SM, Di Somma S, Lewington A: Neutrophil gelatinase-associated lipocalin: ready for routine clinical use? An international perspective. Blood Purif 2014;37: 271-285. 